Short Review

\title{
Personal Observations on the Critical and Unusual Role of Palladium Environment on Reaction Pathways
}

Jacques Muzart *

Institut de Chimie Moléculaire de Reims, UMR 7312, CNRS - Université de Reims ChampagneArdenne, B.P. 1039, 51687 Reims Cedex 2, France; E-Mail: jacques.muzart@univ-reims.fr

* Correspondence: Jacques Muzart; E-Mail: jacques.muzart@univ-reims.fr

Academic Editor: Maxim L. Kuznetsov

Special Issue: Coordination Chemistry and Metal Complexes

Advances in Chemical Research

2020, volume 2 , issue 1

doi:10.21926/acr.2001003
Received: October 10, 2019

Accepted: December 31, 2019

Published: January 08, 2020

\begin{abstract}
This article summarizes some surprising palladoreactions occurring in a transition metal environment, discovered by our team, and the proposed corresponding mechanisms.

\section{Keywords}

Palladium; ethylenic bond; solvent; competing reaction pathways; mechanism; serendipity
\end{abstract}

\section{Introduction}

My interest in palladium in organic chemistry came from the reading of the 1977 Trost review [1] during my postdoctoral research in Corey's laboratory. Back to my Alma matter in late 1978, I was looking for new research subjects. My knowledge in photochemistry, acquired during my doctoral thesis [2], urged me to study the photoreactivity of $\eta^{3}$-allylpalladium complexes. Having obtained 1,5-dienes from the UV light-mediated coupling of the allyl fragments in MeCN under the argon atmosphere [3], I undertook the preparation of squalene from E,E-farnesol [4]. This work led

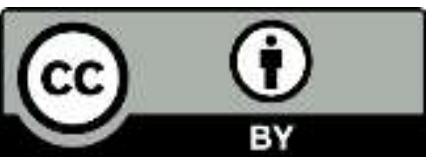

(C) 2020 by the author. This is an open access article distributed under the conditions of the Creative Commons by Attribution License, which permits unrestricted use, distribution, and reproduction in any medium or format, provided the original work is correctly cited. 
to my first observation of the critical role of an unreactive remote ethylenic bond in a palladoreaction. This unexpected observation was an incident of serendipity - that is by accident [5].

These studies were the outcome of forty-year research largely focused on palladium in organic chemistry. The initial topic was chosen, as I, unfortunately, was not aware of older papers from Hojabri who only observed the decomposition of the $\eta^{3}$-allylpalladium complex of $\beta$-pinene under UV irradiation in EtOH, without dimerization of the allyl ligands or effect of oxygen [6, 7]. Actually, we observed, under an oxygen atmosphere, the oxidation of the allyl moieties into conjugated carbonyl compounds [8, 9] even in EtOH [10].

The above role of a remote ethylenic bond and other unexpected results due to the $\mathrm{Pd}$ environment, which we observed over the years, are the matter of this short review.

\section{Remote Ethylenic Bond}

\subsection{Allylpalladium Isomerization}

Using the preparation procedure of bis( $\mu$-chloro)bis $\left(\eta^{3}\right.$-allyl)dipalladium complexes [11-13], I treated $E$,E-farnesyl chloride (1) with substoichiometric amounts of $\operatorname{Pd}_{2}\left(\mathrm{dba}_{3}{ }_{3} \mathrm{CHCl}_{3}\right.$ in benzene at room temperature. Surprisingly, a 1:1 mixture of syn- and anti- $\eta^{3}$-allylpalladium complexes ${ }^{1} 2$ a and $\mathbf{2 b}$ was isolated (Figure 1) [4]. Suspecting the possible role of one of the remote $\mathbf{C}=\mathbf{C}$ bonds of $\mathbf{1}$ in the formation of the mixture, geranyl (3), neryl (4), and phytyl (5) chlorides were treated under the same conditions. A 1:1 mixture of $\mathbf{6 a}$ and $\mathbf{6} \mathbf{b}$ was obtained from 3 and $\mathbf{4}$, while $7 \mathbf{7}(\mathbf{7} \mathbf{a} / \mathbf{7} \mathbf{b}>9)^{2}$ was selectively produced from $\mathbf{5}$. RMN studies of the excess of allylic chlorides $\mathbf{3}$ and $\mathbf{4}$ recovered at the end of the reactions showed that they were not isomerized under the experimental conditions. Stirring the solution of 7 a with a large amount ( $\approx 1000$ equiv.) of cyclohexene or 2 -methylbut-2-ene led only to very poor isomerization at room temperature. Then, a $6: 4$ mixture of $7 \mathbf{a}$ and $\mathbf{7 b}$ was isolated from the reaction of 5 with $\mathrm{Pd}_{2}(\mathrm{dba})_{3} \cdot \mathrm{CHCl}_{3}$ in the presence of 100 equiv. of 2-methylbut2-ene.

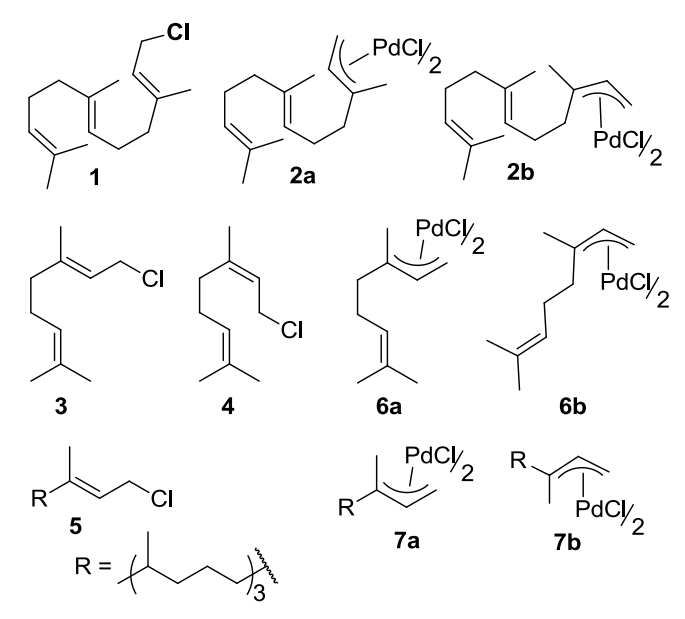

Figure 1 Allylic chlorides and corresponding $\eta^{3}$-allylpalladium complexes.

\footnotetext{
${ }^{1}$ For the meaning of syn- and anti- $\eta^{3}$-allylpalladium complexes, see $[14,15]$.

${ }^{2}$ Mistake in [4]: the $\mathbf{8 a / 8 b}$ value is $>9$ instead of 0.9. In the present review, $7 \mathbf{a}$ and $\mathbf{7 b}$ correspond to $8 \mathbf{a}$ and $8 \mathbf{b}$ of the original paper.
} 
According to the above experiments, the formation of the syn and anti mixtures is promoted by the intra- or intermolecular participation of an isolated $C=C$ bond. Isomerization preceding the formation of the dimeric complex is suspected. This could occur via the $\eta^{3}-\eta^{1}-\eta^{3}$ equilibrium of monomeric allylpalladium intermediates [16] having an ethylenic bond as a ligand (Figure 2).

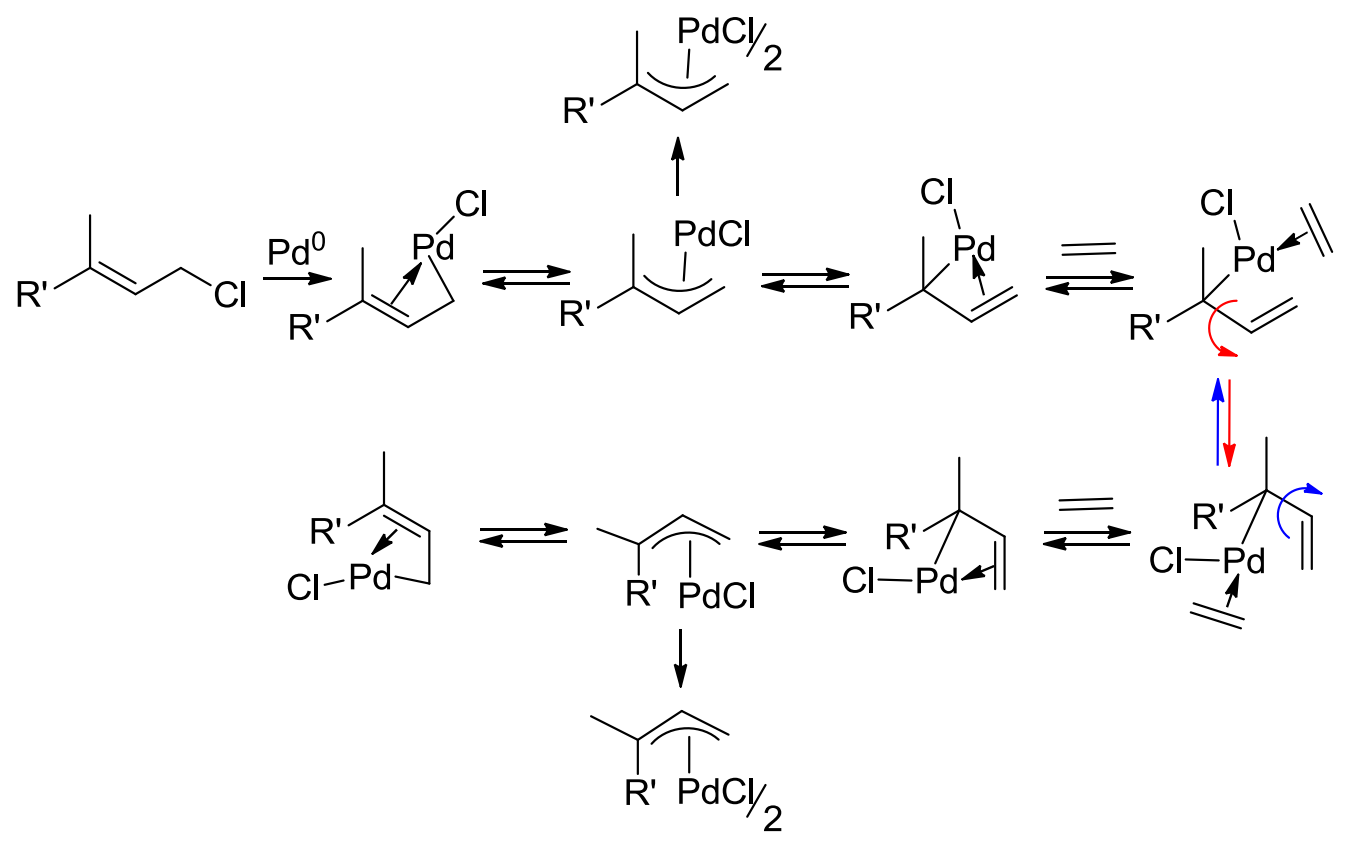

Figure 2 The $\eta^{3}-\eta^{1}-\eta^{3}$ equilibrium.

Subsequently, Åkermark's team rediscovered the formation of the isomeric $\eta^{3}$-allylpalladium complex mixture from geranyl and neryl chlorides $[17,18]$, while Rovis and Johnson provided an overview of olefins influencing the outcome of various reactions [19].

\subsection{Oxidation Inhibition}

In 1995, we disclosed the oxidation of alcohols using catalytic amounts of both $\mathrm{PdCl}_{2}$ and Adogen $464^{3}$ in 1,2-dichloroethane (DCE) containing sodium carbonate [20]. The insoluble palladium dichloride reacts with ammonium salt to yield the soluble palladium salt $\left[\mathrm{PdCl}_{4}\right]^{2-}[21]$, which further oxidizes the alcohol. The resulting reduced $\mathrm{Pd}$ species gets inserted into a $\mathrm{C}-\mathrm{Cl}$ bond of DCE. Subsequent elimination of ethylene regenerates the active catalyst [20, 22]. Using the procedure for the lactonization of 1,4- and 1,5-diols, we surprisingly obtain the formation of lactol $\mathbf{9} \mathbf{u}_{\text {exo }}$ from cis-endo-2,3-bis(hydroxymethyl)bicyclo[2.2.1]hept-5-ene $(\mathbf{8 u})$ although cis-endo-2,3 bis(hydroxymethyl)bicyclo[2.2.1]heptane (8s) provided lactone 10s (Figure 3) [23, 24]. Furthermore, $9 \mathbf{u}_{\text {exo }}$ was almost unchanged under the same experimental conditions without production of $10 \mathrm{u}$, whereas the latter was effectively produced from $9 \mathbf{u}_{\mathbf{e x o}}$ using pyridinium dichromate in $\mathrm{CH}_{2} \mathrm{Cl}_{2}$ (Figure 3) $[25,26$ ] or by the Swern oxidation method [27]. Moreover, our Pd procedure led to the effective oxidation of lactol 11 into the corresponding lactone [24].

\footnotetext{
${ }^{3}$ Adogen 464 is a registered trademark of Ashland Chemical Co. for methyltrialkyl(C8-C10)ammonium chloride.
} 


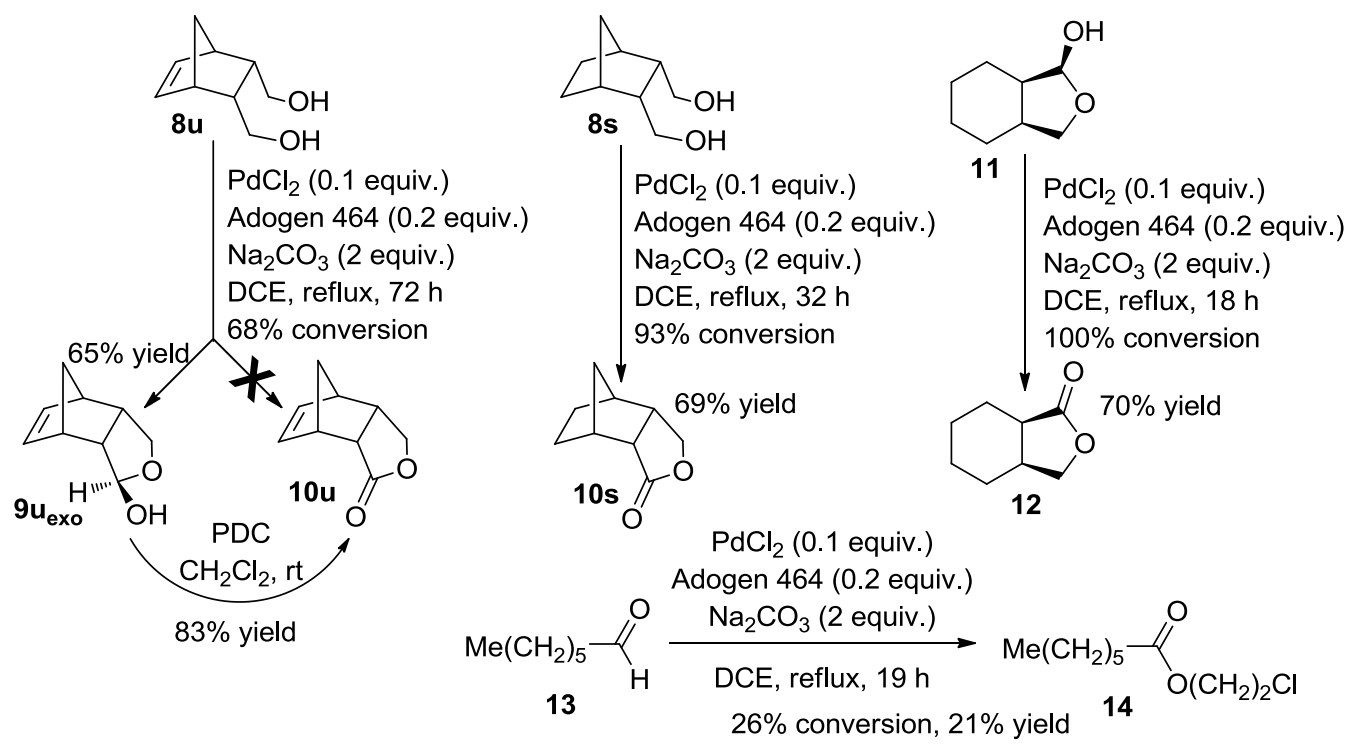

Figure 3 Oxidation of $8 u, 8 s, 9 u_{e x o}, 11$ and 13.

The above results clearly demonstrated that the lack of formation of $10 \mathbf{u}$ from $\mathbf{8 u}$ under Pdconditions was attributable to the $\mathrm{C}=\mathrm{C}$ bond. In order to explain this unusual role, we considered the plausible intermediates of the process (Figure 4; the absence of a juxtaposed $u$ or $s$ letter as suffix to compound numbers of Figure 4 and corresponding text means that these numbers correspond indifferently to either the unsaturated or the saturated substrate.). Hydroxyaldehyde HAd may be in equilibrium with lactols $\boldsymbol{9}_{\text {exo }}$ and $\mathbf{9}_{\text {endo }}$ and may react with $\left[\mathrm{PdCl}_{4}\right]^{2-}$ to give alkoxypalladium aldehyde PAd. The low reactivity of aldehyde $\mathbf{1 3}$ under the reaction conditions (Figure 3) is not in favor of the formation of hydroxyacid HAc from Had ${ }^{4}$. Furthermore, unsaturated HAcu is expected to spontaneously generate lactone $10 \mathrm{u}[29,30]$, which, in fact, was not produced from the Pd-catalyzed reaction of $\mathbf{8} \mathbf{u}$. The pallado-intermediates, $\mathbf{P} \mathbf{9}_{\text {exo }}$ and $\mathbf{P} \mathbf{9}_{\text {endo, may }}$ be produced from $\mathbf{9}_{\text {exo }}$ and $\mathbf{9}_{\text {endo }}($ path $b$ ) or Pad (path $a$ ). Subsequent $\beta$-H elimination would afford 10, but this only occurs for the formation of 10 s.

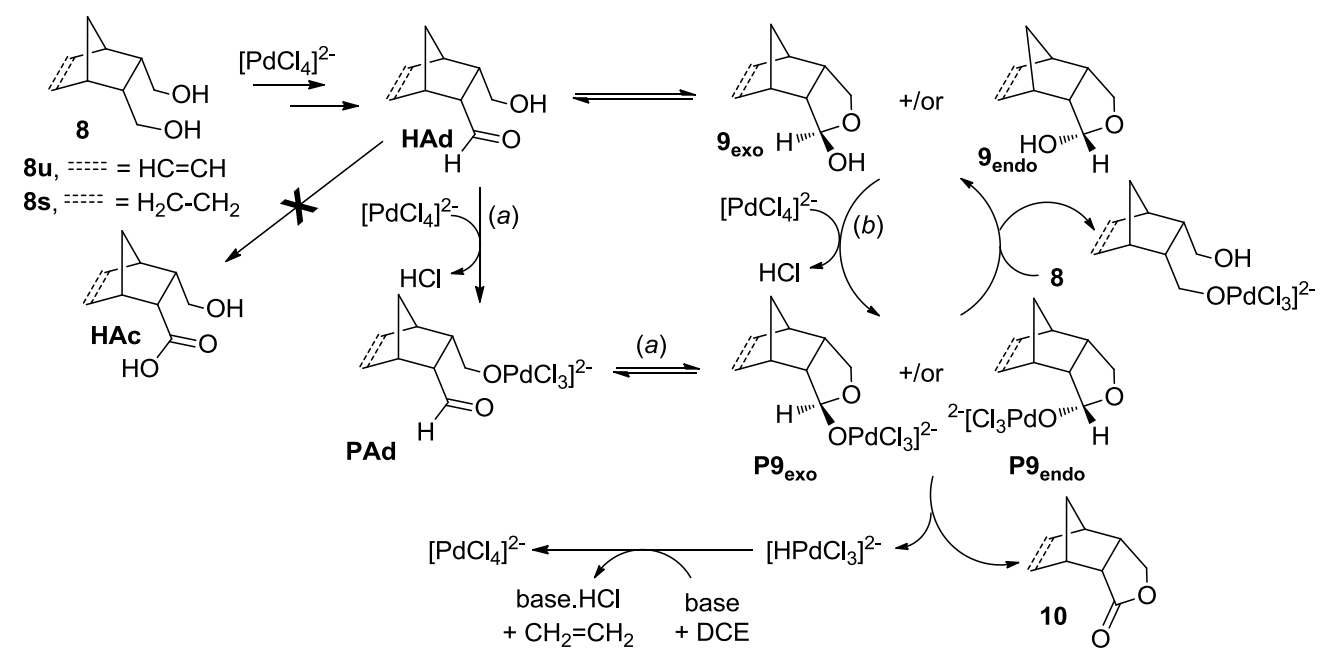

Figure 4 Oxidation of $8 u$ and $8 \mathrm{~s}$; plausible intermediates.

\footnotetext{
${ }^{4}$ Formation of ester 14 from 13 involves the acid as intermediate [28].
} 
The analysis of the literature led us to reject some hypotheses ${ }^{5}$ and to propose that (i) palladation of HAd (path $a$ ) is preferred over that of lactols (path $b$ ), and (ii) the intramolecular reaction of PAd occurs through the stereoselective approach of the alkoxypalladium moiety to one face of the aldehyde to afford $\mathbf{P} \mathbf{9}_{\text {endo. }}$. When the latter is obtained from $\mathbf{8 s}$, the $\beta-\mathrm{H}$ elimination easily occurs to deliver $\mathbf{1 0 s}$. In contrast, $\mathbf{P} \mathbf{9} \mathbf{u}_{\text {endo }}$ obtained from $\mathbf{8 u}$ undergoes a ligand exchange leading to palladacycle PCu (Figure 5). The syn relationship between O-Pd and C-H bonds, which would allow the $\beta-\mathrm{H}$ elimination leading to the carbonyl unit [31, 32], is prevented in PCu. That

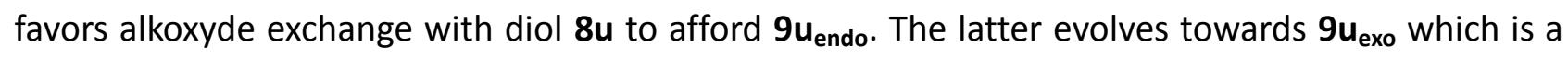
more stable isomer [33-35].

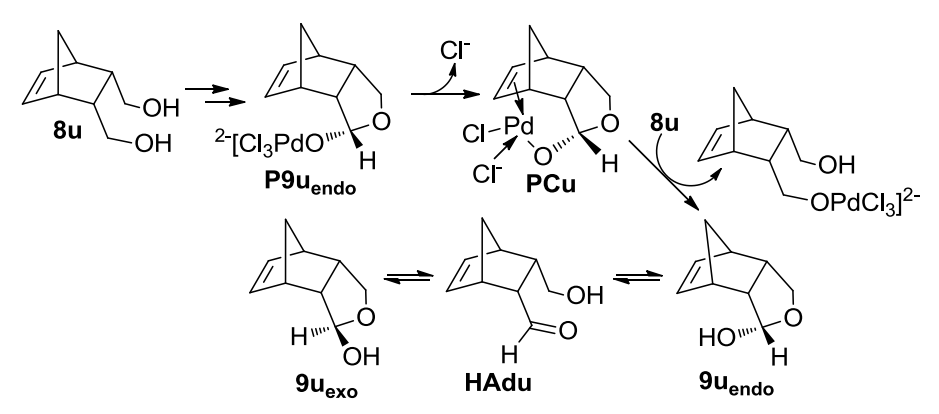

Figure 5 Role of the $\mathrm{C}=\mathrm{C}$ bond in the formation of lactol $9 \mathrm{u}_{\text {exo. }}$.

The apparent absence of $\mathbf{9} \mathbf{u}_{\text {exo }}$ evolution under the aforementioned $\mathrm{Pd}$-catalyzed reaction conditions is a "no reaction" reaction [36, 37], which involves HAdu, $\mathbf{9} \mathbf{u}_{\text {endo, }} \mathbf{P C u}$, alcoholysis and equilibration regenerating the starting substrate.

\section{Oxidation Versus Etherification}

The above catalytic Pd procedure is efficient for the oxidation of 1-indanol (15) into 1-indanone (16) [20]. We obtained a similar result using the soluble palladium salt synthesized from $\mathrm{PdCl}_{2}$ and $n$ - $\mathrm{Bu}_{4} \mathrm{NCl}$ instead of the $\mathrm{PdCl}_{2} /$ Adogen 464 association (Figure 6 , path $a$ ) $[21,38]$. Surprisingly, soluble $(\mathrm{RCN})_{2} \mathrm{PdCl}_{2}$ produced $\mathrm{di}(1$-indanyl) oxide (17) at a high yield, even in the absence of the base (Figure 6, path $b$ ) [38].

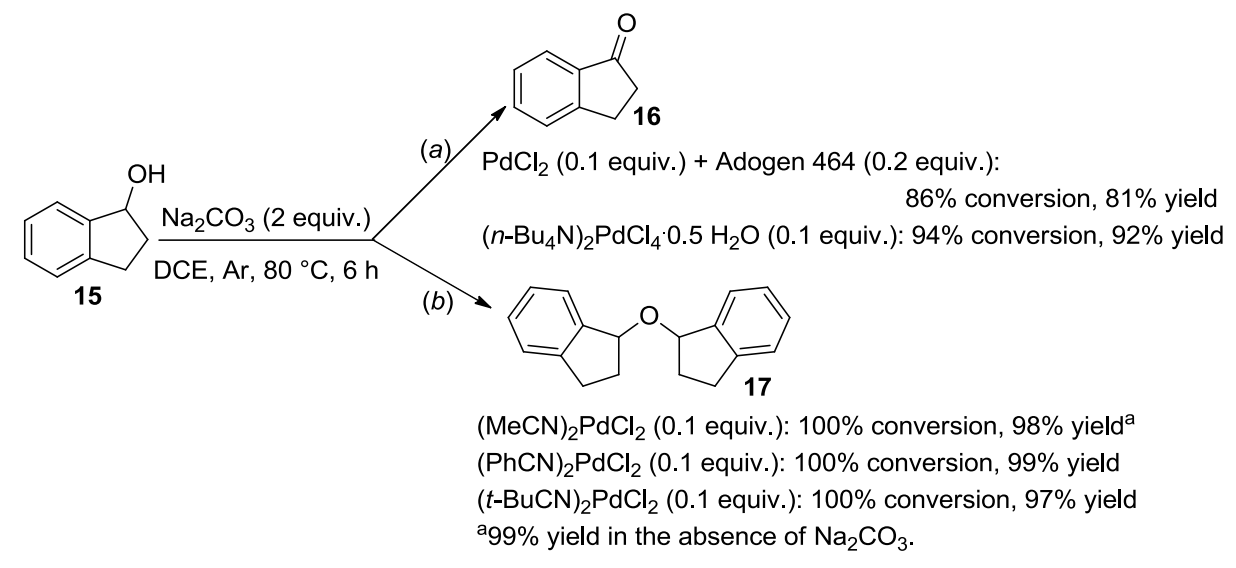

Figure 6 Influence of the Pd environment on the reaction pathways of 1-indanol.

\footnotetext{
${ }^{5}$ See discussion and references in [24].
} 
We rationalized the formation of $\mathbf{1 6}$ and $\mathbf{1 7}$ through two competitive pathways catalyzed by $\mathrm{L}_{2} \mathrm{PdCl}_{2}\left(\mathrm{~L}=\mathrm{Cl}^{-}\right.$or $\left.\mathrm{RCN}\right)$, i.e., with $\left[\mathrm{PdCl}_{4}\right]^{2-}$ and $(\mathrm{RCN})_{2} \mathrm{PdCl}_{2}$, respectively (Figure 7) [38]. In contrast to the anionic catalyst $\left(\mathrm{L}=\mathrm{Cl}^{-}\right)$, the neutral catalyst $(\mathrm{L}=\mathrm{RCN})$ is electrophilic [39-42]. The exchange of ligand between $\mathrm{L}_{2} \mathrm{PdCl}_{2}$ and $\mathbf{1 5}$ affords ${ }^{7} \mathbf{A}$. The evolution of ${ }^{7} \mathbf{A}$ depends on the electrophilicity of $\mathrm{L}_{2} \mathrm{PdCl}_{2}$. Transition metals having Lewis acid properties mediate the formation of ethers from alcohols $[43,44]$. Consequently, ${ }^{7} \mathbf{A}$ formed from the anionic catalyst evolves toward 16 via the ketonization pathway $[20,22]$, while ${ }^{7} \mathbf{A}$ formed from $(\mathrm{RCN})_{2} \mathrm{PdCl}_{2}$ undergoes heterolytic cleavage of the $\mathrm{C}-\mathrm{OH}$ bond leading to the ionic species ${ }^{7} \mathbf{B}$. The latter reacts with $\mathbf{1 5}$ to give ether $\mathbf{1 7}$, water and the starting catalyst.

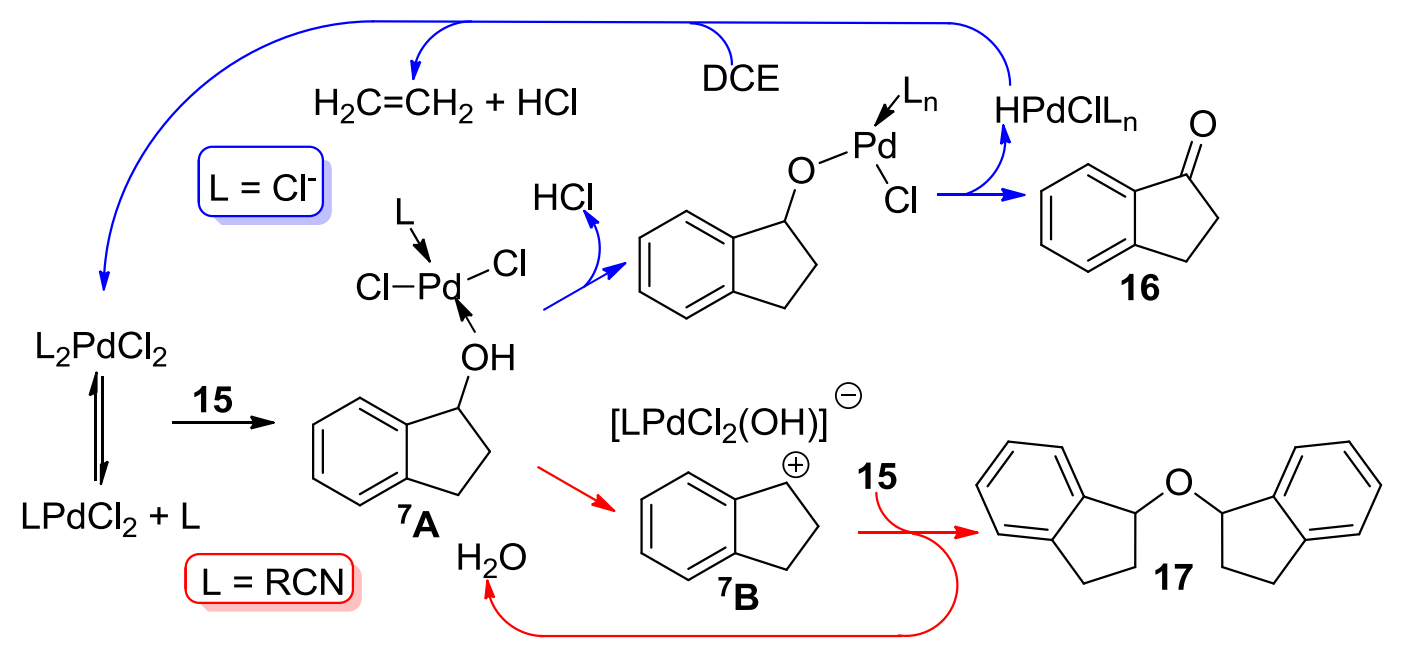

Figure 7 Pathways leading to either oxidation or etherification of 1-indanol.

\section{Solvent-Mediated Pathways}

\subsection{Halide Exchange Versus Alkylation}

As pointed out in the introduction of the present discourse, the irradiation of a bis $(\mu$ chloro)bis $\left(\eta^{3}\right.$-allyl)dipalladium complex in deoxygenated MeCN leads to the allyl coupling. Thus, the I-carvone complex 18 provided 19 (Figure 8, path a) [3]. Then, we looked for different photoreactions [45]. Having observed the lack of photoreactivity of 18 in $\mathrm{CH}_{2} \mathrm{Cl}_{2}$ in the absence of additive, this solvent was firstly chosen for reactions in the presence of organic halides. Halogenexchanged complexes 20 were thus isolated (Figure 8, path b). Changing $\mathrm{CH}_{2} \mathrm{Cl}_{2}$ for $\mathrm{DMF}^{6}$, the reaction with benzyl bromide led to a 1:1 mixture of allylic alkylation and allyl coupling products 21 and 19, respectively (Figure 8 , path $c$ ). These results showed that the species able to temporarily coordinate to palladium, such as MeCN or DMF, are required to form the $\mathrm{C}-\mathrm{C}$ bonds under these irradiation conditions. In fact, we obtained the results similar to those in DMF when the photolysis in $\mathrm{CH}_{2} \mathrm{Cl}_{2}$ was carried with $\mathrm{PPh}_{3}$ as an additive (Figure 8, path $c$ ). The analysis of these reactions by EPR (electron paramagnetic resonance) [51] and CINDP (chemically induced dynamic nuclear polarization) [52] spectroscopies demonstrated their radical character.

\footnotetext{
${ }^{6}$ For the multi-roles of DMF in chemistry, see [46-50].
} 


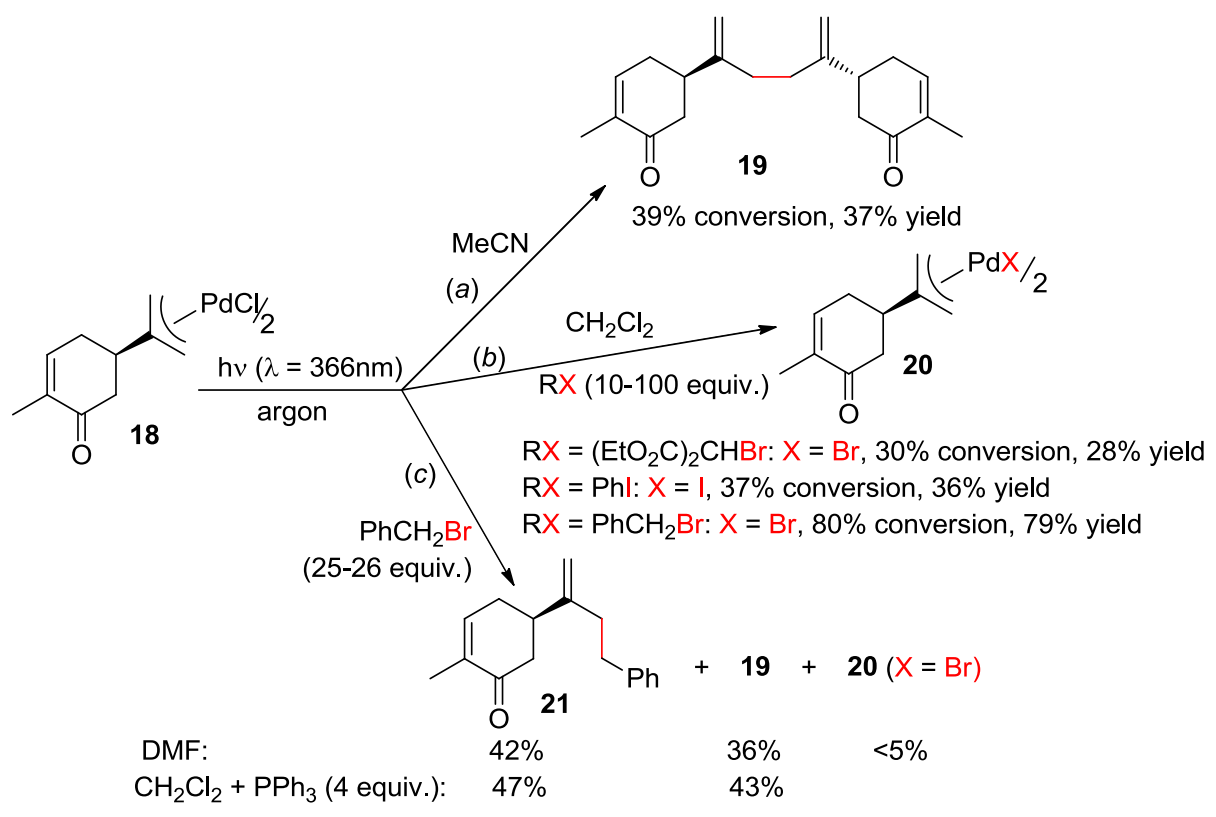

Figure 8 Dependence of the photoreactivity of $\eta^{3}$-allylpalladium complex 18 on the environment.

\section{$4.2 \eta^{1}$ - Versus $\eta^{3}$-Allylpalladium}

Our synthesis of enantiopure vinylmorpholines by the $\mathrm{Pd}^{0}$-catalyzed diastereoselective disubstitution of (Z)-1,4-diacetoxy-2-butene (22) with chiral amino alcohols in THF [53] urged us to examine the isomerization of the substrate [54]. Golding's team briefly reported that treatment of 22 with catalytic $\mathrm{Pd}\left(\mathrm{PPh}_{3}\right)_{4}$ in $\mathrm{PhH}$ at room temperature gave (E)-1,4-diacetoxy-2-butene (23) [55]. At $70-72^{\circ} \mathrm{C}$ in THF, we obtained a mixture of 23 and 1,2-diacetoxy-3-butene (24). The two compounds were also produced in DMF. Monitoring these reactions by ${ }^{1} \mathrm{H} N M R$ resulted in unexpected observations. While $\mathbf{2 3}$ and $\mathbf{2 4}$ were produced in DMF at a constant 23/24 ratio, the latter varied with time in THF (Figure 9). After $15 \mathrm{~min}$, the amount of $\mathbf{2 3}$ decreased to afford the 23/24 equilibrium, indicating that, in THF, $\mathbf{2 4}$ was mainly produced from $\mathbf{2 3}$ rather than from $\mathbf{2 2}$. Subsequent treatments of $\mathbf{2 3}$ and $\mathbf{2 4}$ with $\mathrm{Pd}\left(\mathrm{PPh}_{3}\right)_{4}$ in THF showed an equilibrium between them. According to these results, the isomerization of 22 occurs as depicted in Figure 10 [54].
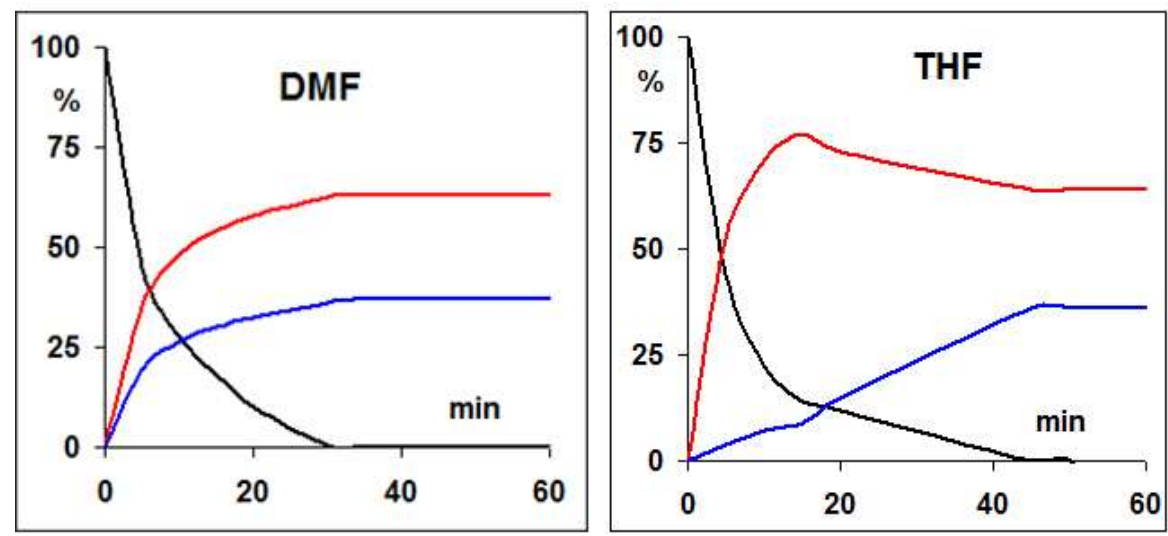

Figure 9 Isomerization of 22 (dark line) into $\mathbf{2 3}$ (red line) and $\mathbf{2 4}$ (blue line) using $\mathrm{Pd}\left(\mathrm{PPh}_{3}\right)_{4}\left(0.05\right.$ equiv.) at $7072^{\circ} \mathrm{C}$ in DMF or THF. 


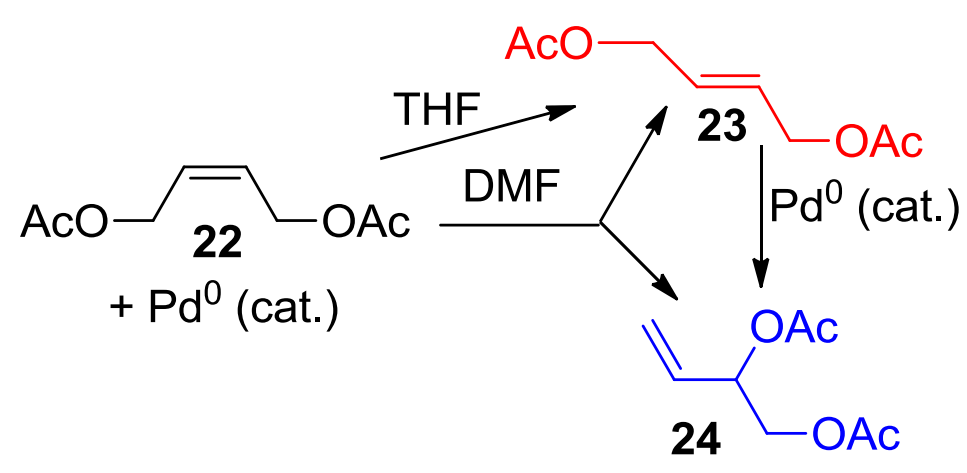

Figure $\mathbf{1 0}$ Formation of $\mathbf{2 3}$ and $\mathbf{2 4}$ according to monitoring analysis.

Allypalladium intermediates with the $\eta^{3}-\eta^{1}-\eta^{3}$ mechanism were proposed for the Z/Eisomerization and the 1,3-transposition of allylic acetates [56]. The proposed reaction pathways of 22 was based on the demonstration given by Amatore and Jutand about the influence of solvent on the species formed from allyl acetate, $\mathrm{Pd}(\mathrm{dba})_{2}$ and $\mathrm{PPh}_{3}$ : "in THF, the acetate ion sticks on the palladium(II) complex (ion pair)" while "in DMF (free ions), the acetate is located far from the cationic n-allylpalladium(II) center" [57, 58]. The reaction of 22 with the catalyst leads to cationic $\eta^{3}$-allylpalladium intermediate ${ }^{11} \mathbf{A}$ that is in equilibrium with the $\eta^{1}$-allyl palladium species ${ }^{{ }^{11} \mathbf{B}}$ (Figure 11). The rotation around the AcOC-C(allyl)Pd bond gives ${ }^{11} \mathrm{C}$ that may afford either 23 by nucleophilic addition of the acetate anion to the external terminus of the allyl group, or $\eta^{3}$ allylpalladium complex ${ }^{11} \mathrm{D}$. The latter may also be formed from $23 .{ }^{11} \mathrm{C}$ being a tight ion-pair in THF, the close proximity of the acetate anion with the allyl moiety favors the efficient addition leading to 23. Whereas in DMF, the separation of the two entities favors the formation of ${ }^{11} \mathbf{D}$. The latter evolves toward 23 and 24.

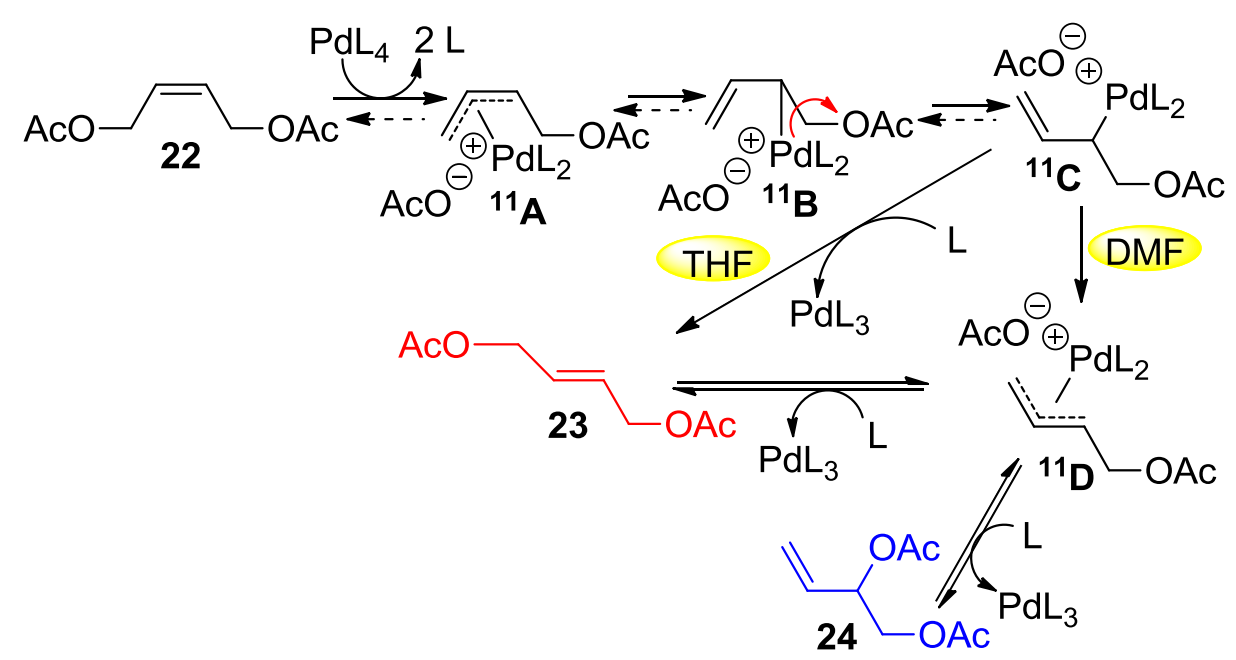

Figure 11 Dependence on the solvent of isomerization intermediates.

$\mathrm{Pd}\left(\mathrm{PPh}_{3}\right)_{4}$-catalyzed isomerization of (Z)-1-(t-butyldimethylsilyloxy)-4-acetoxy-2-butene and (Z)1-(t-butyldiphenylsilyloxy)-4-acetoxy-2-butene led to similar results [59]. Different intermediates have been proposed for the Pd"-catalyzed isomerization of $\mathbf{2 2 ,} \mathbf{2 3}$ and $\mathbf{2 4}$, and the role of the environment of palladium due to THF or DMF on the reactivity has also been highlighted [60]. 


\subsection{Selectivity}

While only allyl alcohol $\mathbf{2 5}$ and allyl ether $\mathbf{2 6}$ were obtained in the presence of acetylacetonate (acacH) from the reaction of 1-acetoxy-1,3-diphenylpropene (27) in $\mathrm{MeOH}$ under basic conditions, the addition of $\mathrm{H}_{2} \mathrm{O}$ provided a 55:40 mixture of $\mathbf{2 6}$ and the cross-coupling product $\mathbf{2 8}$ (Figure 12, paths $a$ and $b$, respectively) [61]. Thus, water may promote a Tsuji-Trost-type reaction under metalfree conditions. The selectivity in 28 was strongly increased (Figure 12, path c) [62] by catalytic amounts of both $(\mathrm{MeCN})_{2} \mathrm{PdCl}_{2}$ and the highly hydrophilic ligand $\mathbf{L}_{\mathbf{H}}$ (Figure 13) that we previously used for Cu-catalyzed allylic acetoxylations in water [63]. Repeating the reaction in the absence of water dramatically decreased the yield of the Tsuji-Trost adduct with the production of the compounds obtained in $\mathrm{MeOH}$ under metal-free conditions (Figure 12, path $d$ ). Thus, water also promotes the Pd catalyzed addition of acacH to 27.

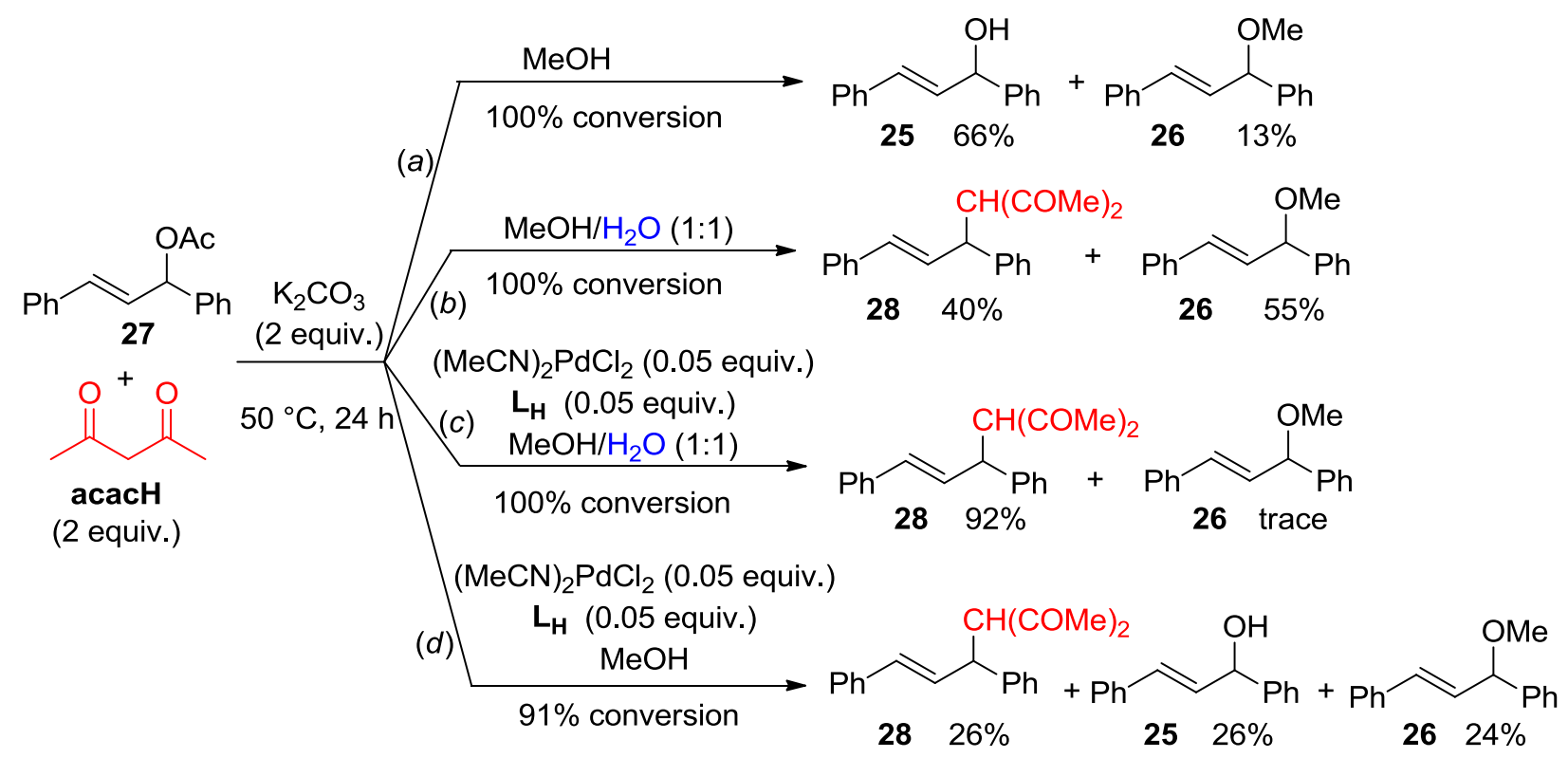

Figure 12 Dependence of selectivity on the presence of water.<smiles>O=C(CN(CCN(CC(=O)NCCO)CC(=O)NCCO)CC(=O)NCCO)NCCO</smiles>

Figure 13 A water-soluble ligand.

ESI-MS (electrospray ionization mass spectrometry) analysis of these reactions led us to assume the possibility of in situ formation of palladium acetylacetonate complex $\mathbf{2 9}$ and the absence of $\eta^{3}$ allylpalladium intermediates (Figure 14) [62]. As a result, it was proposed that 29 , which would be a more effective nucleophile than acacK and MeOK, reacts with the water-activated substrate. The efficient recycling of the catalyst [62] showed that a Pd" complex is truly immobilized in water, and led to assume the production of water-coordinated palladium species such as $\mathbf{3 0}$ as intermediates of the catalytic cycle. 


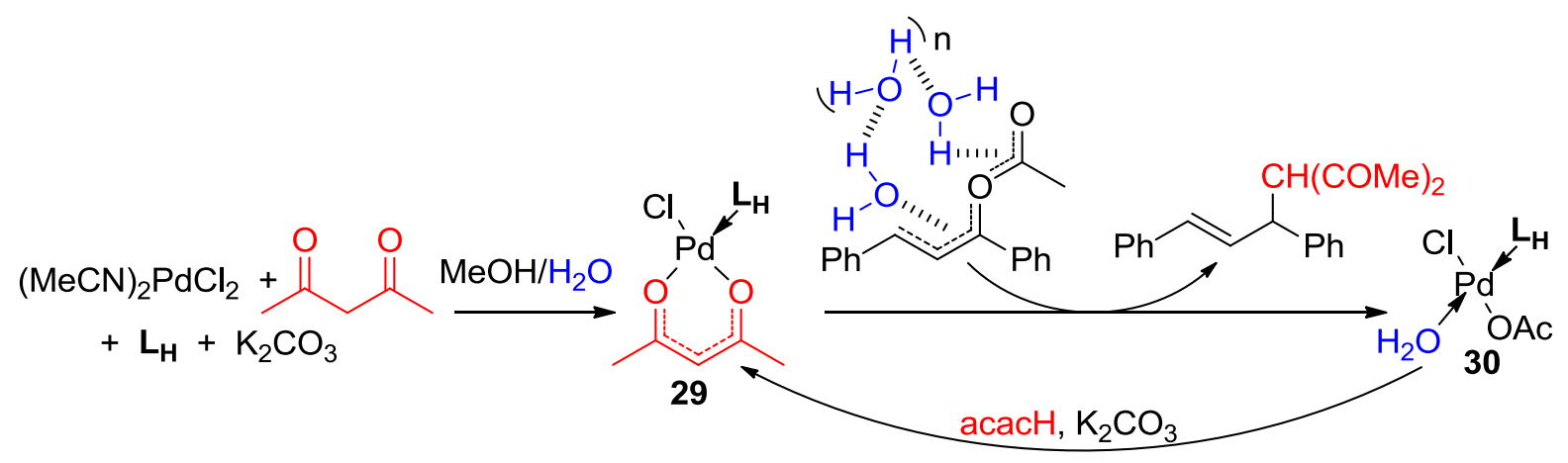

Figure 14 Formation of a Tsuji-Trost product without $\eta^{3}$-allylpalladium intermediate.

\section{Conclusion}

The above examples highlight the unexpected observations made in the course of our studies, on the effect of the palladium environment on the outcome of reactions. Of course, several critical roles of the palladium environment have also been documented in the literature. These influences on the reactivity have attracted tremendous attention toward palladium in organic chemistry. New reactions and mechanisms are often serendipitously discovered but nevertheless, in most cases, they are the outcomes of deep investigations and reflections rather than good fortune [5].

\section{Acknowledgments}

I am grateful to colleagues and students from the Universities of Barcelona, Girona, Grenoble, Lille, Lodz, Marseille, Oldenburg, Prague, Reims and York whose names are cited in the references, for their involvement in the above reactions. I thank CNRS for the freedom in the choice of my research activities.

\section{Author Contribution}

Jacques Muzart did the whole writing of the review.

\section{Competing Interests}

The author has declared that no competing interests exist.

\section{References}

1. Trost BM. Organopalladium intermediates in organic synthesis. Tetrahedron. 1977; 33: 26152649.

2. Muzart J. Doctoral thesis: Préparation, réactivité photochimique d' $\alpha$-époxycétones et de $\beta$ dicétones. Paris: Reims University; 1976.

3. Muzart J, Pete JP. Preparation of 1,5 -dienes by photolysis of $\eta^{3}$-allylpalladium complexes. J Chem Soc Chem Commun. 1980: 257-258.

4. Muzart J, Pete J. Complexes $\eta^{3}$-allylpalladium: Isomérisation et photolyse; synthèse du squalène. Bull Soc Chim Fr. 1984: 56-58.

5. Rulev AY. Serendipity or the art of making discoveries. New J Chem. 2017; 41: 4262-4268. 
6. Hojabri F. Some reactions of $\pi$-allylic palladium complexes prepared from $\beta$-pinene. J Appl Chem Biotechnol. 1973; 23: 205-207.

7. Hojabri F. Polymerisation of bicyclohepta-(2,5)-diene with palladium- $\pi$-complexes. J Appl Chem Biotechnol. 1973; 23: 601-605.

8. Muzart J, Pale P, Pete JP. Preparation of conjugated carbonyl compounds by photolysis of $\eta^{3}$ allylpalladium complexes. J Chem Soc Chem Commun. 1981: 668-669.

9. Muzart J, Pale $P$, Pete J. Photooxydation régiosélective de complexes $\eta^{3}$-allylpalladium: Accès à des composés carbonylés $\alpha, \beta$-insaturés fonctionnalisés en $\gamma$. Tetrahedron Lett. 1983; 24 : 4567-4568.

10. Muzart J, Pale $P$, Pète J, Riahi A. Induction par la lumière de l'oxydation des complexes $\eta^{3}$ allylpalladium par l'oxygène moléculaire. Bull Soc Chim Fr. 1988: 731-739.

11. Ukai T, Kawazura H, Ishii Y, Bonnet J, Ibers JA. Chemistry of dibenzylideneacetonepalladium(0) complexes: I. Novel tris(dibenzylideneacetone)dipalladium(solvent) complexes and their reactions with quinones. J Organomet Chem. 1974; 65: 253-266.

12. Ito $\mathrm{T}$, Hasegawa $\mathrm{S}$, Takahashi $\mathrm{Y}$, Ishii $\mathrm{Y}$. Chemistry of dibenzylideneacetone-palladium(0) complexes: II. Preparation and oxidation reactions of novel palladium $\pi$-olefinic and $\pi$ acetylenic complexes. J Organomet Chem. 1974; 73: 401-409.

13. Kurosawa H, Ogoshi S, Kawasaki Y, Murai S, Miyoshi M, Ikeda I. Novel dependency of stereochemistry upon metal, ligand, and solvent in oxidative addition of allylic chloride to palladium(0) and platinum(0) complexes. J Am Chem Soc. 1990; 112: 2813-2814.

14. Lukas J, Ramakers-Blom J, Hewitt T, De Boer J. Syn-and anti-(1-alkyl-r-allyl)palladium chlorides. J Organomet Chem. 1972; 46: 167-177.

15. Frost CG, Howarth J, Williams JM. Selectivity in palladium catalysed allylic substitution. Tetrahedron Asymmetry. 1992; 3: 1089-1122.

16. Breutel C, Pregosin PS, Salzmann R, Togni A. An unusual, selective $\eta^{3}-\eta^{1}$ allyl isomerization in a chiral allylic alkylation catalyst. J Am Chem Soc. 1994; 116: 4067-4068.

17. Åkermark B, Hansson S, Krakenberger B, Vitagliano A, Zetterberg K. Alkylation of ( $\pi-$ allyl)palladium systems. Mechanism and regiocontrol. Organometallics. 1984; 3: 679-682.

18. Åkermark B, Vitagliano A. Reactivity and syn-anti isomerization of ( $\eta^{3}$-geranyl)-and $\left(\eta^{3}\right.$ neryl)palladium complexes. Evidence for electronic control of the regiochemistry of nucleophilic addition. Organometallics. 1985; 4: 1275-1283.

19. Johnson JB, Rovis T. More than bystanders: The effect of olefins on transition-metal-catalyzed cross-coupling reactions. Angew Chem Int Ed Engl. 2008; 47: 840-871.

20. Aït-Mohand S, Hénin F, Muzart J. Palladium(II)-mediated oxidation of alcohols using 1,2dichloroethane as $\mathrm{Pd}(0)$ reoxidant. Tetrahedron Lett. 1995; 36: 2473-2476.

21. Bouquillon S, du Moulinet d'Hardemare A, Averbuch-Pouchot MT, Hénin F, Muzart J. Synthesis and characterization of monomeric and dimeric palladium(II)-ammonium complexes: Their use for the catalytic oxidation of alcohols. Polyhedron. 1999; 18: 3511-3516.

22. Rothenberg G, Humbel S, Muzart J. Palladium-catalysed oxidation of alcohols to carbonyl compounds with 1,2-dichloroethane as the primary oxidant: A theoretical study. J Chem Soc Perkin Trans 2. 2001: 1998-2004.

23. Aït-Mohand S, Muzart J. Palladium-catalyzed oxidative cyclization of 1,4-and 1,5-diols in 1,2dichloroethane. J Mol Catal A: Chem. 1998; 129: 135-139. 
24. Aït-Mohand S, Hénin F, Muzart J. Palladium-catalyzed oxidations: Inhibition of a Pd-H elimination by coordination of a remote carbon-carbon double bond. Organometallics. 2001; 20: $1683-1686$.

25. Aït-Mohand S. Doctoral thesis: Catalyse de réactions d'oxydation : Utilisation du percarbonate de sodium et régénération d'espèces palladiées actives par le 1,2-dichloroéthane: Reims University; 1997.

26. Taniguchi T, Ogasawara K. Specific asymmetric mono-epoxidation of Meso 2,3-syn-bis-allylic alcohols having a bicyclo [2.2.1] heptane framework. Tetrahedron Lett. 1997; 38: 433-436.

27. Taniguchi T, Goto Y, Ogasawara K. Preparation of a promising cyclobutanone chiral building block: Its stereochemistry and utilization. Synlett. 1997: 707-709.

28. Aït-Mohand S, Levina A, Muzart J. Pyridinium dichromate-catalyzed oxidative cleavage of $\alpha$ functionalized benzylic alcohols by sodium percarbonate under phase-transfer conditions. Synth Commun. 1995; 25: 2051-2059.

29. Jaeschke G, Seebach D. Highly enantioselective ring opening of cyclic meso-anhydrides to isopropyl hemiesters with Ti-TADDOLates: An alternative to hydrolytic enzymes?. J Org Chem. 1998; 63: 1190-1197.

30. March J. Advanced organic chemistry. 4th Ed. New York: John Wiley; 1992. p. 393

31. Chung K, Banik SM, De Crisci AG, Pearson DM, Blake TR, Olsson JV, et al. Chemoselective Pdcatalyzed oxidation of polyols: Synthetic scope and mechanistic studies. J Am Chem Soc. 2013; 135: 7593-7602.

32. Li Y, Lin Z. Understanding the reaction mechanisms of Pd-catalysed oxidation of alcohols and domino oxidation-arylation reactions using phenyl chloride as an oxidant. Org Chem Front. 2014; 1: 1188-1196.

33. Corey E, Palani A. A method for the selective oxidation of 1,4-diols to lactols. Tetrahedron Lett. 1995; 36: 3485-3488.

34. Corey E, Palani A. A mechanistic model for the selective oxidation of 1,4-diols to $\gamma$-lactols by o-iodoxybenzoic acid. Tetrahedron Lett. 1995; 36: 7945-7948.

35. Lieb F, Niewöhner U, Wendisch D. 6-(3-Carbamoylbicyclo [2.2.1] hept-2-yl) hexansäuren, eine neue klasse von TxA2-antagonisten. Liebigs Ann Chem. 1987: 607-615.

36. Berson JA, Willcott MR. Bredt rule interdictions of cyclopropane rearrangements. The vinylnortricyclenes. J Org Chem. 1965; 30: 3569-3572.

37. Baldwin JE, Dunmire DA. The "no reaction" reaction of 1-vinylnortricyclene to tricyclo [4.2.1.0 $0^{3,7}$ ] non-3-ene. J Org Chem. 2000; 65: 6791-6794.

38. Bouquillon S, Hénin F, Muzart J. Critical role of the coordination environment of palladium dichloride on the course of its reaction with secondary benzylic alcohols: Selective oxidation or etherification catalysts. Organometallics. 2000; 19: 1434-1437.

39. Sen A, Lai TW. Catalysis by solvated transition-metal cations. Novel catalytic transformations of alkenes by tetrakis(acetonitrile)palladium ditetrafluoroborate. Evidence for the formation of incipient carbonium ions as intermediates. J Am Chem Soc. 1981; 103: 4627-4629.

40. Sen A, Lai TW. Oligomerization and isomerization of olefins by $\eta^{3}$-allyl complexes of palladium. The role of the allyl group. Organometallics. 1983; 2: 1059-1060.

41. Lipshutz BH, Pollart D, Monforte J, Kotsuki H. Pd(II)-catalyzed acetal/ketal hydrolysis/exchange reactions. Tetrahedron Lett. 1985; 26: 705-708. 
42. Tenaglia A, Kammerer F. Palladium(II)-catalyzed dehydrative cyclization of cis-4Alkylcycloalken-2-ols. Synthesis of tricyclic spiroketals in a one-pot sequence. Synlett. 1996: 576-578.

43. Aït-Mohand S, Muzart J, Lunak S. Chlorides and acetylacetonates of transition metals as catalysts for the oxidation of 1 -indanol by sodium percarbonate. Chem Ber. 1997; 130: 16551658.

44. Salehi P, Iranpoor N, Behbahani FK. Selective and efficient alcoholyses of allylic, secondaryand tertiary benzylic alcohols in the presence of iron(III). Tetrahedron. 1998; 54: 943-948.

45. De Poorter B, Muzart J, Pete JP. Photoreactivity of $\left(\eta^{3}\right.$-allyl)palladium complexes in the presence of organic halides. Organometallics. 1983; 2: 1494-1497.

46. Muzart J. N,N-dimethylformamide: Much more than a solvent. Tetrahedron. 2009; 65: 83138323.

47. Ding S, Jiao N. N,N-dimethylformamide: A multipurpose building block. Angew Chem Int Ed Engl. 2012; 51: 9226-9237.

48. Batra A, Singh $\mathrm{P}$, Singh $\mathrm{KN}$. Cross dehydrogenative coupling (CDC) reactions of $\mathrm{N}, \mathrm{N}$ disubstituted formamides, benzaldehydes and cycloalkanes. European J Org Chem. 2016: 4927-4947.

49. Le Bras J, Muzart J. Recent uses of $N, N$-dimethylformamide and $N, N$-dimethylacetamide as reagents. Molecules. 2018; 23: E1939.

50. Le Bras J, Muzart J. N,N-dimethylformamide and $\mathrm{N}, \mathrm{N}$-dimethylacetamide as carbon, hydrogen, nitrogen, and/or oxygen sources. Solvents as reagents in organic synthesis: Reactions and applications. Weinheim: Wiley-VCH; 2017. p. 199-314.

51. Crozet MP, Muzart J, Pale P, Tordo P. Photolyse de complexes $\eta^{3}$-allylpalladium: Etude par résonance paramagnétique électronique des nitroxydes allyliques formés en présence de nitrosodurène. J Organomet Chem. 1983; 244: 191-200.

52. Vermeersch G, Marko J, Muzart J. Photoreactivity of $\eta^{3}$-allylpalladium complexes studied by CIDNP. J Chem Soc Perkin Trans 2. 1986: 383-389.

53. Thorey C, Wilken J, Hénin F, Martens J, Mehler T, Muzart J. Diastereoselective synthesis of vinylmorpholines by palladium-catalyzed tandem allylic substitutions using enantiopure aminoalcohols as bifunctional nucleophiles. Tetrahedron Lett. 1995; 36: 5527-5530.

54. Bouquillon S, Muzart J. Palladium(0)-catalyzed isomerization of (Z)-1,4-diacetoxy-2-butene: Dependence of $\eta^{1}$ - or $\eta^{3}$-allylpalladium as a key intermediate on the solvent polarity. European J Org Chem. 2001: 3301-3305.

55. Crilley MM, Golding BT, Pierpoint C. Palladium(II)-catalysed rearrangements of allylic acetates in the syntheses of methyl (10E,12Z)-9-hydroxyoctadeca-10,12-dienoate ( $\alpha$-dimorphecolate) and (2E,4Z)-deca-2,4-dienal. J Chem Soc Perkin Trans 1. 1988: 2061-2067.

56. Trost BM, Van Vranken DL. Asymmetric transition metal-catalyzed allylic alkylations. Chem Rev. 1996; 96: 395-422.

57. Amatore C, Jutand A, Meyer G, Mottier L. Evidence of the reversible formation of cationic $\pi$ allylpalladium(II) complexes in the oxidative addition of allylic acetates to palladium(0) complexes. Chemistry. 1999; 5: 466-473.

58. Jutand $A$. The use of conductivity measurements for the characterization of cationic palladium(II) complexes and for the determination of kinetic and thermodynamic data in palladium-catalyzed reactions. Eur J Inorg Chem. 2003:2017-2040. 
59. Zawisza AM, Muzart J. Palladium(0)-catalyzed isomerization of (Z)-1-functionalized-4-acetoxy2-butenes: Solvent and substituent effects. J Organomet Chem. 2010; 695: 62-66.

60. Zawisza AM, Bouquillon S, Muzart J. Palladium(II)-catalyzed isomerization of (Z)-1,4diacetoxy-2-butene: Solvent effects. European J Org Chem. 2007: 3901-3904.

61. Chevrin C, Le Bras J, Hénin F, Muzart J. Water-mediated transition-metal-free tsuji-trost-type reaction. Tetrahedron Lett. 2003; 44: 8099-8102.

62. Chevrin C, Le Bras J, Hénin F, Muzart J, Pla-Quintana A, Roglans A, et al. Allylic substitution mediated by water and palladium: Unusual role of a palladium(II) catalyst and ESI-MS analysis. Organometallics. 2004; 23: 4796-4799.

63. Le Bras J, Muzart J. Water-soluble and reusable copper catalyst for the allylic benzoyloxylation of olefins. Tetrahedron Lett. 2002; 43: 431-433.

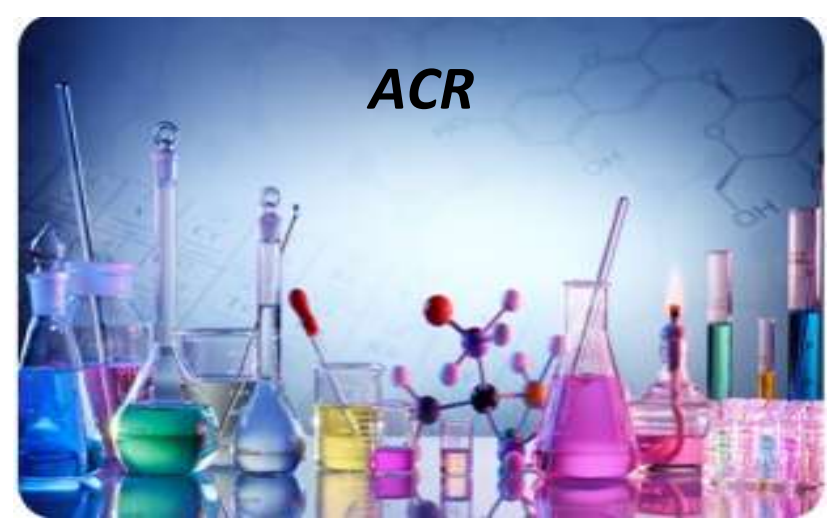

Enjoy $A C R$ by:

1. Submitting a manuscript

2. Joining in volunteer reviewer bank

3. Joining Editorial Board

4. Guest editing a special issue

For more details, please visit:

http://www.lidsen.com/journals/acr 